
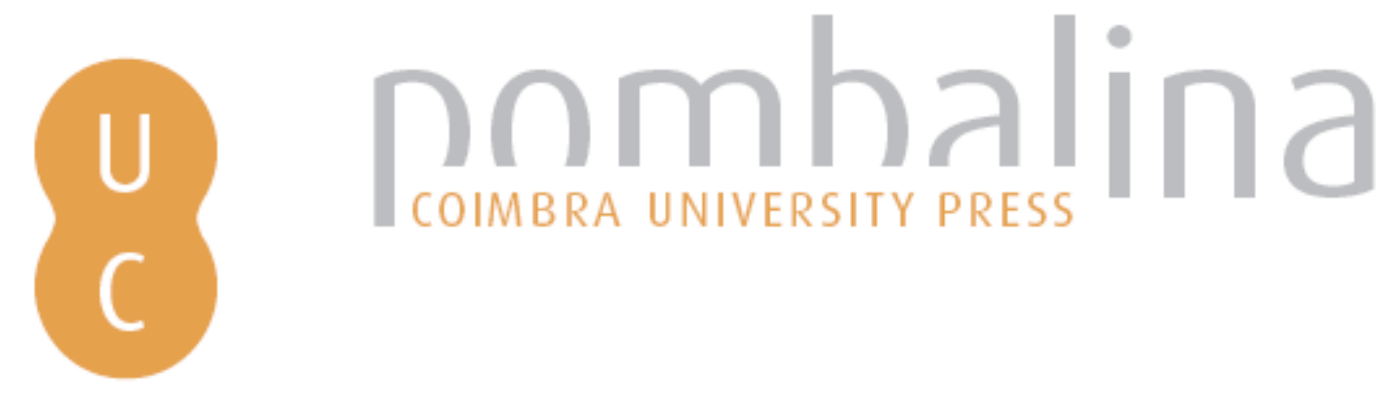

\title{
Diálogo entre a ciência e os utilizadores potencialidades e fragilidades na temática dos riscos
}

\author{
Autor(es): $\quad$ Tedim, Fantina; Oliveira, Sandra; Nunes, Adélia; Ferreira, Cármen; \\ Lourenço, Luciano
}

Publicado por: Imprensa da Universidade de Coimbra

URL persistente:

URI:http://hdl.handle.net/10316.2/35752

DOI:

DOI:http://dx.doi.org/10.14195/978-972-8330-23-1_7

Accessed : $\quad$ 30-Oct-2019 11:55:08

A navegação consulta e descarregamento dos títulos inseridos nas Bibliotecas Digitais UC Digitalis, UC Pombalina e UC Impactum, pressupõem a aceitação plena e sem reservas dos Termos e Condições de Uso destas Bibliotecas Digitais, disponíveis em https://digitalis.uc.pt/pt-pt/termos.

Conforme exposto nos referidos Termos e Condições de Uso, o descarregamento de títulos de acesso restrito requer uma licença válida de autorização devendo o utilizador aceder ao(s) documento(s) a partir de um endereço de IP da instituição detentora da supramencionada licença.

Ao utilizador é apenas permitido o descarregamento para uso pessoal, pelo que o emprego do(s) título(s) descarregado(s) para outro fim, designadamente comercial, carece de autorização do respetivo autor ou editor da obra.

Na medida em que todas as obras da UC Digitalis se encontram protegidas pelo Código do Direito de Autor e Direitos Conexos e demais legislação aplicável, toda a cópia, parcial ou total, deste documento, nos casos em que é legalmente admitida, deverá conter ou fazer-se acompanhar por este aviso.

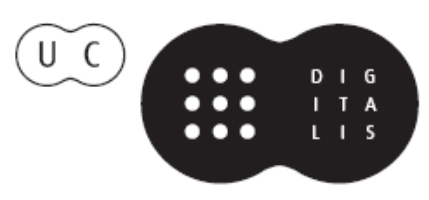




\section{REALIDADES E DESAFIOS NA GESTÃO DOS RISCOS}

\section{Diálogo entre Ciência e Utilizadores}

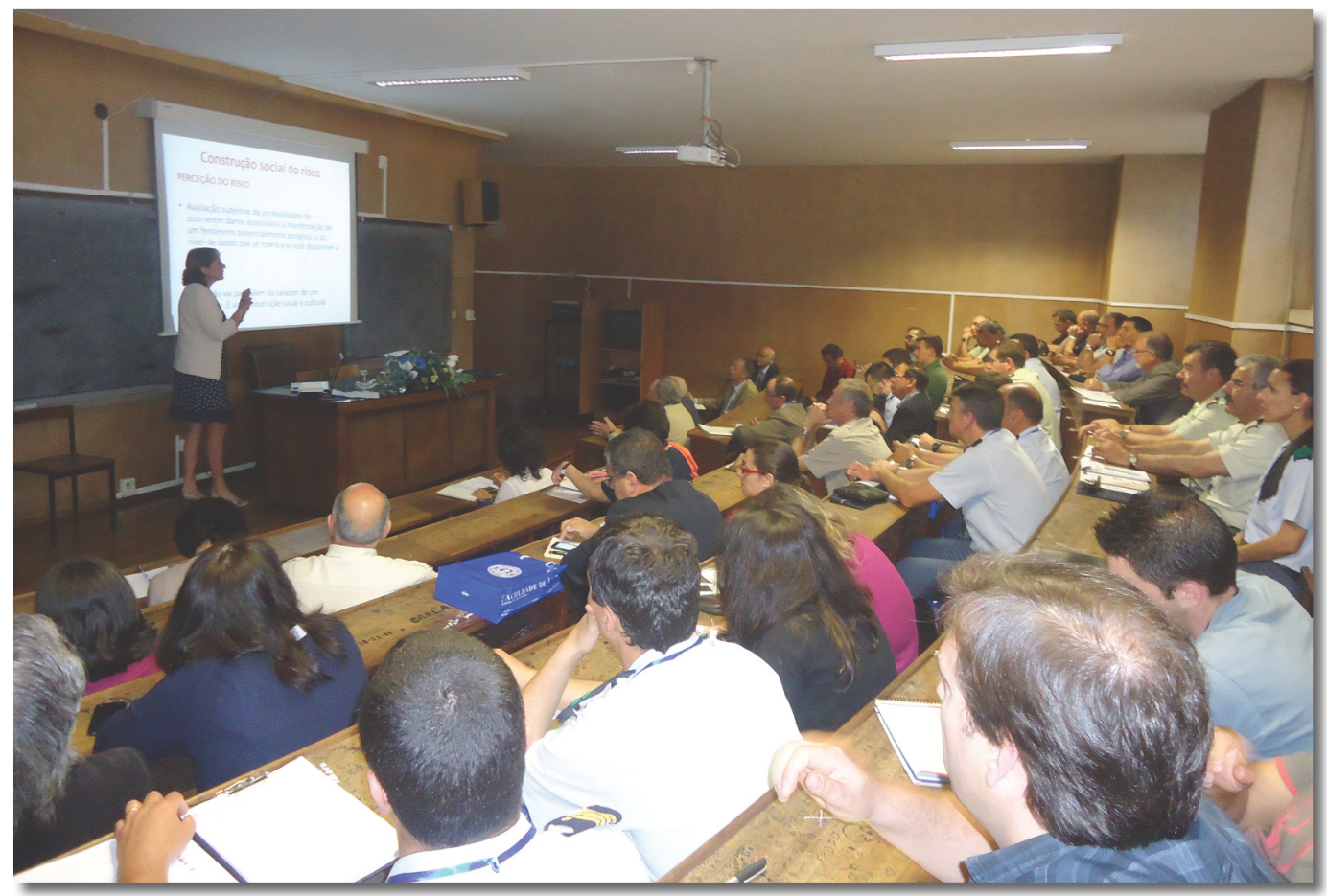

Núcleo de Investigação Científica de Incêndios Florestais

Faculdade de Letras da Universidade de Coimbra

Coimbra 


\title{
Capítulo VII \\ DIÁLOGO ENTRE A CIÊNCIA E OS UTILIZADORES \\ POTENCIALIDADES E FRAGILIDADES NA TEMÁTICA DOS RISCOS
}

\author{
Fantina Tedim \\ CEGOT e Departamento de Geografia \\ Faculdade de Letras da Universidade do Porto \\ ftedim@letras.up.pt \\ Sandra Oliveira \\ NICIF- Núcleo de Investigação Cientifica de Incêndios Florestais \\ Universidade de Coimbra \\ sisoliveira@gmail.com \\ Adélia Nunes \\ CEGOT e Departamento de Geografia \\ Faculdade de Letras da Universidade de Coimbra \\ adelia.nunes@ci.uc.pt \\ Cármen Ferreira \\ CEGOT e Departamento de Geografia \\ Faculdade de Letras da Universidade do Porto \\ dra.carmenferreira@gmail.com \\ Luciano Lourenço \\ CEGOT e Departamento de Geografia \\ Faculdade de Letras da Universidade de Coimbra \\ luciano@uc.pt
}

\section{Introdução}

O diálogo entre os investigadores e os atores sociais, como um processo estruturado de comunicação, tem assumido nos últimos anos uma atenção crescente (WELP et al., 2006). A orientação estratégica do Horizonte 2020, no sentido de promover o desenvolvimento de soluções para responder aos desafios societais, reforça a necessidade do diálogo entre os investigadores e os utilizadores, fundado na interatividade e complementaridade que responsabilize ambos pela cocriação de conhecimento (WeLP et al., 2006), a sua operacionalização e otimização.

No domínio dos riscos e da gestão de crises, este diálogo assume particular importância, considerando o âmbito alargado desta temática, a interdisciplinaridade que a envolve e, por conseguinte, a diversidade de conceitos e linhas de pensamento que se cruzam. De facto, a gestão dos riscos e das crises é cada vez mais complexa, requerendo muita informação e conhecimentos multidisciplinares que se encontram dispersos assim como um reforço de abordagens de investigação-ação-investigação para otimizar conhecimentos e recursos.

A presente investigação resultou de uma reunião de trabalho que ocorreu no âmbito do Seminário "Diálogos entre Ciência e Utilizadores: Realidades e desafios na gestão do risco", que permitiu reunir investigadores e operacionais provenientes da Autoridade Nacional de Proteção Civil (ANPC), do Instituto de Conservação da Natureza e das Florestas (ICNF), da Guarda Nacional Republicana (GNR) e dos Corpos de Bombeiros (CB). Orientou-se em torno de três objetivos:

1. Identificar as vantagens e limitações da prática atual de gestão dos riscos e das crises, segundo a opinião dos operacionais;

2. Discutir a proposta de um modelo do risco apresentado na primeira sessão de trabalho do já referido seminário; 


\section{Realidades e desafios na gestão dos riscos \\ - Diálogo entre ciência e utilizadores -}

3. Compreender como os utilizadores se relacionam com a comunidade científica e percecionam o impacto da produção científica nacional na gestão dos riscos e das crises.

A apreciação do modelo atual de gestão de riscos e crises, por parte de atores sociais e de investigadores, foi o primeiro passo para compreender a importância de promover o estabelecimento de uma cultura de parceria entre os investigadores e os utilizadores que permita desenvolver sinergias, sem esgotarem o campo de atuação de cada um dos intervenientes. Para além disso, a análise das características da relação entre investigadores e utilizadores forneceu informações cruciais para identificar a necessidade de reforçar a colaboração entre as duas comunidades, orientar o desenvolvimento da investigação científica, aumentar a visibilidade e o impacto social da produção científica, assim como para compreender problemas que os utilizadores enfrentam na avaliação e gestão dos riscos e das emergências e, consequentemente, as respostas que gostariam que a investigação científica fornecesse.

Neste artigo argumenta-se que reforçar a comunicação e a colaboração entre a comunidade científica e a comunidade dos utilizadores, contribuirá para aumentar a eficácia na gestão dos riscos e das crises bem como para criar uma sociedade mais resiliente. Por um lado, permitirá aos utilizadores ter acesso mais rápido e fácil à produção científica; facilitará a avaliação da eficácia das estratégias e medidas de gestão do risco e das crises; e poderá contribuir para melhorar a comunicação entre as organizações e os cidadãos, promovendo o seu envolvimento na construção de uma sociedade mais resiliente. Por outro lado, a colaboração entre as duas comunidades fomentará o impacto societal da investigação científica, ao direcioná-la para a resolução de problemas concretos da sociedade e para a apresentação de medidas inovadoras e mais eficazes de gestão dos riscos e das crises; facilita a implementação de um modelo de investigação-ação-investigação, aumentando a responsabilidade dos investigadores na orientação das políticas; e motiva os investigadores a preocuparem-se com a operacionalização da sua investigação e a forma de a comunicar aos utilizadores e ao setor político. Uma dinâmica colaborativa permitirá aumentar a eficácia na gestão e um impacto mais alargado da investigação científica.

\section{Metodologia}

A realização de um seminário com duas sessões distintas (uma que decorreu de manhã, foi constituída pelos Painéis "Ciência" e "Ação" e, a outra, realizada durante a tarde, foi organizada por grupos de trabalho, seguida por uma mesa redonda) foi o método eleito para promover o diálogo entre os utilizadores e a comunidade científica. Nos Painéis "Ciência" e "Ação" vários investigadores, provenientes de diferentes áreas científicas, apresentaram questões conceptuais e metodológicas dos riscos (ver capítulos I a VI). Na sessão da tarde, os participantes do seminário foram divididos por quatro grupos de trabalho, nos quais os utilizadores expressaram livremente a sua experiência e opinião sobre a temática dos riscos, de que todos eles são próximos devido à sua atividade profissional. Nesta sessão de grupos de trabalho, participaram 32 pessoas, das quais 23 utilizadores (ANPC - 3, ICNF-1, GNR - 16; CB - 3; 3 estudantes de $2 .^{\circ}$ e $3 .^{\circ}$ ciclos e 6 investigadores.

O principal método de investigação social utilizado foi o de grupos de discussão que permitiram a partilha de pontos de vista e ideias dos participantes de uma forma estruturada, e, consequentemente, a produção de informação primária. É uma técnica particularmente útil na análise de temas que podem suscitar opiniões divergentes, ou em que se quer aprofundar o conhecimento sobre a temática. A interação em cada grupo foi moderada por um investigador. Previamente, estabeleceram-se seis questões que foram apresentadas e debatidas em cada um dos grupos. Estas questões que estruturaram a discussão destinaram-se a conhecer a opinião dos participantes sobre as potencialidades e as fragilidades do atual modelo de gestão do risco e de emergências, assim como a avaliar em que medida o modelo conceptual do risco apresentado no Painel "Ciência" do seminário contribuiria para uma melhor práxis, quer na prevenção dos riscos, quer na gestão das crises. 
A técnica da discussão em grupo que é uma fonte primária de informação qualitativa foi combinada com uma abordagem quantitativa através da resposta dos utilizadores a um questionário. Após a discussão, foi pedido a cada participante que respondesse a um questionário com 14 questões, das quais sete eram perguntas abertas; estas questões não eram apenas direcionadas para os principais objetivos dos grupos de discussão, mas versaram também sobre a aplicabilidade da produção científica nacional na temática dos riscos naturais e antrópicos, assim como sobre a comunicação e a colaboração entre os investigadores e os utilizadores.

Neste artigo, apresentam-se os resultados dos quatro grupos de discussão e as respostas aos questionários apenas dos 23 profissionais da ANPC, ICNF, GNR e CB, e que são, genericamente, designados de utilizadores. Atendendo ao reduzido número de participantes provenientes de algumas das instituições, os resultados referentes a cada tipo de organização não serão utilizados, tendo-se optado por apresentar apenas os resultados globais. Para a exploração da informação quantitativa recolhida, foi apenas utilizada análise estatística descritiva.

\section{Resultados e discussão}

\section{Grupos de discussão}

A discussão em grupo foi orientada por seis questões em torno de dois aspetos principais. Primeiro, identificar as principais dificuldades na atual gestão do risco; segundo, conhecer a apreciação dos utilizadores sobre o modelo de risco apresentado no Painel "Ciência" (ver capítulo $\mathrm{VI}$ ), de modo a compreender as suas vantagens e limitações para reforçar a política de prevenção e gestão dos riscos naturais e antrópicos.

\section{A atual prática de gestão do risco: identificação de problemas}

\section{a) Prevenção versus mitigação de consequências}

Uma das fragilidades identificadas relaciona-se com a fraca expressão da prevenção dos riscos e uma aposta, fundamentalmente, baseada na mitigação de consequências resultantes da manifestação do risco. Esta situação é extremamente evidente no caso dos incêndios florestais, com o desequilíbrio entre os recursos financeiros destinados à prevenção e ao combate. A prevenção foi considerada, pelos participantes, como um investimento a longo prazo mas com uma melhor relação custo-benefício. Foram apresentados exemplos referentes ao sucesso de campanhas de redução dos incêndios florestais associados à renovação de pastagens no norte de Portugal. A aposta no combate foi considerada uma imposição política, pois os participantes nos grupos de discussão reconheceram a importância de alocar mais recursos à prevenção e menos ao combate.

\section{b) Operacionalização dos planos}

Em relação à operacionalização dos planos foi referido não haver uma clara ligação entre o planeamento de emergência e a ação. A gestão das emergências passou de um modelo em que não havia coordenação e onde havia abusos, excessos e má utilização de recursos, para um modelo demasiado rígido. Não há margem de manobra das organizações locais para decidirem o que fazer. Por exemplo, no passado, os corpos de bombeiros eram autónomos e faziam frequentes saídas do quartel que funcionavam como vigilância. Hoje, para os carros saírem do quartel, têm de comunicar ao Centro Distrital de Operações e Socorro (CDOS) e obter autorização.

Os planos estão bem elaborados em termos de estrutura e de conteúdo, mas na prática não funcionam, por várias razões: não conseguem prever todas as situações e muitas decisões que não foram previstas nos planos têm de ser tomadas no teatro de operações; os planos são impostos por regulamentação nacional, não prevendo a adaptação às realidades locais, o que 


\section{Realidades e desafios na gestão dos riscos \\ - Diálogo entre ciência e utilizadores -}

dificulta e fragiliza a sua aplicação; nem sempre é cumprido o que está estabelecido no plano por falta de recursos (p. ex., nem sempre é feita a gestão de combustível prevista no Plano Operacional Municipal- POM) e/ou existem falhas na atuação das pessoas e das instituições.

Quando se está no terreno, é necessário tomar decisões na hora e lidar com imprevistos, e isso depende da experiência e da formação das pessoas que têm que tomar essas decisões. Existem situações que obrigam a lidar com o "perigo dentro do perigo", que não estão definidas a priori no esquema geral de gestão de riscos, e que exigem um investimento adicional na formação e na aquisição de conhecimentos rigorosos por parte dos operacionais e decisores, para que possam ser aplicadas as ações mais ajustadas e eficientes aos acontecimentos inesperados.

\section{c) Gestão de riscos: legislação e governança}

$\mathrm{Na}$ gestão de riscos, foi defendido valorizar mais as "lições aprendidas", ou seja, avaliar as ações tomadas e os resultados, e integrar o que se aprendeu, a nível técnico e operacional, no processo de análise de risco a montante, de modo a permitir a melhoria constante de todo o sistema. Esta avaliação dos aspetos positivos e limitações e a sua integração na melhoria no processo de prevenção e gestão de riscos não é, atualmente, concretizada de forma sistemática, sobretudo pela rigidez nos conteúdos dos próprios planos.

Foi referido que Portugal possui uma boa legislação relativamente à gestão do risco e redução dos danos, todavia, não há certeza da sua efetiva aplicação. Ainda no que concerne à legislação, apontou-se que esta deveria ser o mais abstrata possível, pois quanto mais específica, mais difícil se torna a sua aplicação. Foi sugerido que a "linguagem" legislativa fosse mais clara, de forma a permitir um maior entendimento da mesma pelo cidadão comum.

Foi, igualmente, mencionada a importância de aumentar o número de incêndios florestais investigados quanto à causa de ignição e incremento da eficácia no apuramento da respetiva causalidade. Foi proposto que, na elaboração da cartografia de risco de incêndio florestal, os tipos de ocupação do solo fossem substituídos por modelos de combustíveis.

Para muitos dos utilizadores, os atuais problemas na gestão dos riscos e das crises estão, sobretudo, relacionados com a governança. Foi salientado que enquanto todas as entidades envolvidas na gestão dos riscos não se entenderem e não se articularem entre si, não haverá "supermodelo" que reforce a política de prevenção. Foi, no entanto, referido que o novo modelo conceptual que foi proposto no Painel "Ciência" pode permitir reforçar a política de prevenção dos riscos naturais e antrópicos, mas terá que ser articulado com todos os outros instrumentos de gestão.

O Plano Nacional de Defesa da Floresta Contra Incêndios foi mencionado como um exemplo muito positivo da atual gestão dos incêndios florestais por requerer a coordenação entre organismos, que passaram a falar uma linguagem comum e a trabalhar em conjunto, nomeadamente ao nível da prevenção. A única fragilidade é a falta de meios para o operacionalizar na íntegra. Há dificuldade em cumprir integralmente as atribuições que estão definidas para cada organização, por manifesta falta de meios.

Relativamente a algumas condições que dificultam a gestão do risco, sobretudo de incêndio florestal, foram salientadas:

- Inexistência de um cadastro da propriedade rústica que facilitaria, nomeadamente, a eficácia da fiscalização das medidas de proteção e prevenção previstas na lei assim como a responsabilização dos privados;

- O absentismo e o abandono dos espaços florestais por parte dos produtores nacionais;

- Os incêndios florestais são vistos como uma oportunidade de negócio para vários atores, pelo que será difícil controlá-los se não se tornar a floresta rentável;

- O Estado não dá o exemplo perante os privados, pois não faz uma adequada gestão do combustível nas suas propriedades. 


\section{O modelo conceptual proposto: apreciação conceptual e terminológica}

\section{a) Esquema conceptual}

O modelo conceptual proposto (ver capítulo $\mathrm{VI}$ ) foi bem recebido pelos intervenientes nos grupos de discussão e, genericamente, obteve o acordo dos participantes. As definições dos conceitos apresentados pareceram claras para os diversos participantes. 0 esquema não foi considerado muito simples, o que foi compreendido pois a realidade é muito complexa. Aliás, para ser completo, o esquema deveria ainda integrar outras informações, como as causas dos riscos e perigos e a análise dos interesses instalados, por exemplo, que não aparecem pela dificuldade de os materializar.

Todavia, como seria expectável e desejável, foram feitas algumas considerações e sugestões. o principal ponto de divergência revelou-se na definição dos conceitos de risco e perigo. Embora a maioria dos participantes concordasse com o esquema apresentado, outros defenderam que o perigo está a montante do risco, e não a jusante como é proposto pelo modelo, uma vez que neste último conceito está inerente a perda de bens. 0 conceito de crise levantou algum debate, pois houve quem referisse que este deveria ser entendido a um nível mais elevado, ou seja, ao nível da capacidade governativa, enquanto outros referiram que a crise é a plena manifestação do risco e que já está presente quando o incidente/acidente é real. Para muitos dos participantes, o aspeto mais relevante do modelo foi a conceptualização da vulnerabilidade.

As principais alterações propostas ao modelo conceptual apresentado foram: substituição do termo capacidade de resposta por capacidade de antecipação (como um elemento integrante da vulnerabilidade); integração da capacidade de resposta ao nível da operacionalização (na manifestação do risco/perigo e na crise); integrar as vertentes individual e das comunidades na capacidade de resposta; e inclusão da incerteza no esquema conceptual.

\section{b) Terminologia}

A nível terminológico, a principal questão prendeu-se com a definição do termo hazard. Habitualmente, tem sido traduzido, na literatura especializada, por perigo (JuLĩ̃o et al., 2009) ou por perigosidade (VERDE, 2008; VERDE e ZÊZZERE, 2010). O modelo apresentado propõe como tradução processo potencialmente perigoso (PPP), que obteve a concordância de alguns dos participantes mas foi amplamente criticada por outros, nomeadamente porque é uma expressão longa e deveria ser apenas uma palavra. Perante a dificuldade de chegar a acordo, foi sugerido que fosse mantido o termo hazard, mas a opinião foi claramente a favor de que deveria ser procurada uma tradução. Foi consensual que, ao nível académico, a tradução de hazard possa não ser necessária; contudo, ao nível operacional, tem que haver uma tradução, não por "processo potencialmente perigoso", mas sim por um termo único, mais simples. Foi salientado pelos participantes que qualquer alteração de terminologia na área dos riscos requer a concordância a nível político e tem de ser publicada em legislação, para que possa ser operacionalizada.

Foi, igualmente, mencionado que muitas vezes, ao nível prático, são utilizados termos que não foram apresentados no esquema e que surgiram da necessidade de ajustar o comportamento ao nível da ação. Por exemplo, a GNR, quando fala com a população, utiliza o termo ameaça e ameaça de risco de incêndio florestal, sendo estes os termos que incitam a tomar medidas de proteção. Noutro exemplo, a ANPC não fala de crise, mas de emergência. Também foi notado no modelo conceptual apresentado, que não foram considerados os conceitos de calamidade e de perigosidade.

Por várias vezes foi reforçada a ideia da necessidade de uma definição clara e uniforme dos conceitos associados ao risco entre os especialistas, que deveriam ser depois aplicados a nível nacional. Foi afirmado que a não uniformização desses conceitos implica, para os operacionais, uma maior dificuldade nos termos a utilizar, podendo estar em causa a capacidade de resposta, pois, como referiram - "É preciso saber do que falamos". 


\section{Realidades e desafios na gestão dos riscos \\ - Diálogo entre ciência e utilizadores -}

\section{Análise do questionário}

\section{O planeamento e a gestão do risco e da emergência}

A maior parte dos utilizadores consideraram que a gestão dos riscos e da emergência evoluíram muito nos últimos anos, o que contribuiu para reduzir os danos, embora reconheçam que os principais progressos se registaram na resposta a situações de crise e menos na prevenção (TABELA I). Todavia, quando questionados sobre se a "redução dos danos se explicava principalmente por uma rápida e eficaz resposta de emergência", as opiniões foram muito diversificadas, o que demonstrou haver utilizadores que consideram que alguns progressos na prevenção dos riscos também puderam ser constatados. Os utilizadores reconheceram que a prevenção é a melhor estratégia para reduzir os impactes da manifestação dos riscos, embora a maioria deles (78\%) tenha considerado haver falta de uma verdadeira política de prevenção.

Uma das áreas em que pode ser desenvolvida a prevenção dos riscos é no ordenamento do território. O Programa Nacional da Política de Ordenamento do Território (Lei n. ${ }^{\circ}$ 58/2007 de 4 de setembro) considerou os riscos um dos vetores que intervêm na estrutura do modelo territorial. Os participantes na reunião consideraram inadequada a integração da prevenção de riscos no ordenamento do território realizada até ao momento, sendo importante reforçá-la.

TABELA I - Opinião sobre o atual modelo de gestão do risco.

\begin{tabular}{|l|c|}
\hline \multicolumn{1}{|c|}{ Questões } & $\% *$ \\
\hline A prevenção é a melhor forma para reduzir os impactos da manifestação dos riscos & 96 \\
\hline Há falta de uma verdadeira política de prevenção dos riscos & 78 \\
\hline $\begin{array}{l}\text { A avaliação e gestão dos riscos evoluíram muito nos últimos anos e têm contribuído } \\
\text { para reduzir os danos relacionados, por exemplo, com as cheias, os incêndios } \\
\text { florestais, a erosão costeira }\end{array}$ & 70 \\
\hline $\begin{array}{l}\text { A atual prática da gestão do risco está muito mais vocacionada para responder a } \\
\text { situações de crise/emergência do que efetivamente prevenir os riscos }\end{array}$ & 65 \\
\hline $\begin{array}{l}\text { A redução dos danos explica-se principalmente por uma rápida e eficaz resposta de } \\
\text { emergência }\end{array}$ & 44 \\
\hline $\begin{array}{l}\text { A forma como a prevenção de riscos é inserida no ordenamento do território é } \\
\text { adequada }\end{array}$ & 26 \\
\hline $\begin{array}{c}\text { *As percentagens referem-se às respostas dos utilizadores que "concordaram" ou “concordaram totalmente" } \\
\text { com o conteúdo dos itens mencionados. }\end{array}$ \\
\hline
\end{tabular}

Os utilizadores consideraram fundamental a elaboração de planos e de cartografia para apoiar a decisão na gestão do risco (TABELA II). Na elaboração de planos, foram identificados quatro constrangimentos:

1. Nem sempre está disponível informação científica para os realizar, de modo a que possam ser instrumentos eficazes, quer na prevenção do risco quer na gestão da emergência;

2. Há planos que são elaborados por imposição legal, embora não thes reconheçam importância no âmbito da gestão do risco e das crises;

3. A estrutura dos planos é demasiado rígida, não permitindo integrar aspetos adequados às realidades locais assim como, segundo a opinião de alguns dos utilizadores, também limita a possibilidade de integração das lições aprendidas com a gestão das crises/emergências na retificação dos planos de prevenção e de emergência;

4. A falta de uma verdadeira política de prevenção, pois os utilizadores consideraram que a gestão do risco está demasiado focada na construção de planos para gerir operacionalmente as crises/emergências. 
TABELA II - Opinião sobre o planeamento da gestão do risco.

\begin{tabular}{|c|c|}
\hline \multicolumn{1}{|c|}{ Questões } & $\%^{*}$ \\
\hline $\begin{array}{l}\text { Há planos que se fazem por imposição legal embora não se reconheça a sua } \\
\text { importância no âmbito da gestão do risco e das crises/emergências }\end{array}$ & 83 \\
\hline $\begin{array}{c}\text { A cartografia de risco atualmente existente é uma ferramenta fundamental para } \\
\text { quem tem de fazer prevenção dos riscos }\end{array}$ & 74 \\
\hline $\begin{array}{l}\text { A prática de avaliação e gestão do risco está demasiado focada na construção de } \\
\text { planos para gerir operacionalmente as crises/emergências }\end{array}$ & 74 \\
\hline $\begin{array}{l}\text { A estrutura dos planos é demasiado rígida e não permite integrar aspetos adequados } \\
\text { às realidades locais }\end{array}$ & 74 \\
\hline $\begin{array}{l}\text { Os planos são extremamente úteis mas frequentemente não há informação para os } \\
\text { realizar de modo a que possam ser instrumentos importantes na prevenção do risco }\end{array}$ & 70 \\
\hline $\begin{array}{l}\text { As liçães aprendidas com a gestão das crises/emergência são utilizadas para retificar } \\
\text { os planos de prevenção e de emergência }\end{array}$ & 48 \\
\hline $\begin{array}{l}\text { *As percentagens referem-se às respostas dos utilizadores que "concordaram" ou “concordaram totalmente" } \\
\text { com o conteúdo dos itens mencionados. }\end{array}$ \\
\hline
\end{tabular}

Gestão do risco e da emergência: disponibilidade de conhecimento científico

Os utilizadores manifestaram opiniões discordantes sobre a existência de conhecimento científico adequado sobre como prevenir os riscos (com 44\% de respostas concordantes e 35\% de respostas discordantes) (TABELA III). Para a maior parte dos participantes, os municípios não dispõem da informação e do conhecimento necessários para promover a redução do risco, mas já em relação à informação e conhecimento necessários para promover a gestão das catástrofes as opiniões são discordantes, o que aponta para experiências distintas.

Questionados sobre o seu próprio conhecimento de conceitos centrais na temática dos riscos (risco, vulnerabilidade e resiliência), os utilizadores afirmaram possuir bom conhecimento, sendo os conceitos de vulnerabilidade e resiliência os que suscitam mais dúvidas, já que $48 \%$ dos inquiridos manifestaram algum ou total desconhecimento.

TABELA III - Opinião sobre o conhecimento científico disponível e a gestão do risco.

\begin{tabular}{|l|c|}
\hline \multicolumn{1}{|c|}{ Questões } & $\% *$ \\
\hline Tenho um bom conhecimento da definição de risco & 78 \\
\hline $\begin{array}{l}\text { Os municípios não dispõem da informação e do conhecimento necessários para } \\
\text { tomarem as decisões adequadas para promover a redução do risco. }\end{array}$ & 52 \\
\hline $\begin{array}{l}\text { Tenho um bom conhecimento sobre a importância da avaliação da vulnerabilidade para } \\
\text { desenvolver ações que reduzam as perdas e danos provocados pela manifestação } \\
\text { dos riscos }\end{array}$ & 52 \\
\hline $\begin{array}{l}\text { Tenho um bom conhecimento sobre o que significa construir sociedades resilientes } \\
\text { aos riscos naturais e antrópicos }\end{array}$ & 52 \\
\hline $\begin{array}{l}\text { É possível reduzir os riscos, há conhecimento sobre como o fazer mas não há recursos } \\
\text { nem financeiros nem técnicos }\end{array}$ & 48 \\
\hline É possível prevenir os riscos mas há pouco conhecimento sobre como o fazer & 44 \\
\hline $\begin{array}{l}\text { Os municípios não dispõem da informação e do conhecimento necessários para } \\
\text { tomarem as decisões adequadas para promover uma gestão eficaz das crises/ } \\
\text { emergências }\end{array}$ & 39 \\
\hline $\begin{array}{c}\text { *As percentagens referem-se às respostas dos utilizadores que "concordaram” ou “concordaram totalmente" } \\
\text { com o conteúdo dos itens mencionados. }\end{array}$ \\
\hline
\end{tabular}




\section{Realidades e desafios na gestão dos riscos \\ - Diálogo entre ciência e utilizadores -}

\section{Pontos fortes da atual política de prevenção dos riscos e de gestão das crises}

A principal vantagem do atual modelo de gestão dos riscos e das crises, mencionada pelos utilizadores, foi a adoção de uma atuação uniforme e sistematizada em todo o território nacional. A criação do Sistema Integrado de Operações de Proteção e Socorro (SIOPS) permite uma resposta muito mais rápida e eficaz em situação de emergência. Segundo os intervenientes no seminário, o enquadramento político e a estrutura organizativa que foram criados permitiram:

- Rentabilizar recursos humanos e materiais;

- Diminuir a vulnerabilidade dos intervenientes quando estão no teatro de operações;

- Preparar melhor a resposta, tentando prever vários tipos de situações e adequando os meios e as estratégias, contribuindo, efetivamente, para a redução de danos.

\section{Alterações propostas à política e praxis vigente}

Foram várias as alterações sugeridas à política vigente, cuja aceitação como foi salientado pelos inquiridos, está dependente da disponibilidade financeira e da vontade dos responsáveis políticos. As principais propostas de alteração surgiram na melhoria da prevenção, na cultura das organizações e na governança dos riscos e das crises (TABELA IV).

\section{Opinião sobre o esquema conceptual}

O esquema conceptual apresentado no seminário (ver capítulo $\mathrm{VI}$ ), foi considerado compreensível, embora cerca de metade dos participantes $(52 \%)$ o tenham classificado como complexo (TABELA V). Para a maior parte dos intervenientes, representa algum avanço face aos modelos existentes, nomeadamente porque permite um melhor suporte conceptual para a prevenção dos riscos. A dupla vertente do esquema, interligando a parte conceptual com a operacionalização, mereceu uma opinião favorável, embora seja importante melhorar alguns aspetos, conforme foi discutido nos grupos de trabalho e antes apresentado no ponto "O modelo conceptual proposto: apreciação conceptual e terminológica” (p. 77).

Em relação à abrangência do esquema para cobrir todo o tipo de opções técnicas, mais de metade dos utilizadores que responderam à questão, avaliaram desfavoravelmente o esquema conceptual.

\section{Opiniões sobre a governança do risco e das crises}

A maioria dos participantes (68\% de respostas concordantes) declararam que o município representa a melhor escala para fazer prevenção dos riscos, assim como para gerir as emergências (TABELA IV). Todavia, também reconheceram como fundamental a articulação entre o nível municipal e as estruturas hierarquicamente superiores (i.e. regional/distrital e nacional).

A Lei de Bases da Proteção Civil (Lei n. ${ }^{\circ} 27 / 2006$, de 3 de julho) no seu artigo $1 .^{\circ}$, menciona que a proteção civil é desenvolvida por todas as instituições e organizações públicas e privadas, assim como pelos cidadãos, mas os inquiridos consideraram que, no atual quadro, a prevenção dos riscos envolve muito pouco os cidadãos, que deverão ser mais ativos na implementação de medidas de prevenção e autoproteção e menos dependentes da proteção civil.

A dificuldade na colaboração, não só entre o setor público e privado mas também entre as instituições com atribuições/responsabilidades na gestão dos riscos e das emergências, foi realçada por $59 \%$ dos participantes, que reconheceram que, apesar dessa dificuldade, há aceitação de sugestões para aumentar a eficácia da atuação. Esta podia ainda ser maximizada se a informação necessária para a gestão do risco e das emergências fosse 
partilhada de uma forma adequada entre as instituições do Estado, o que a maior parte dos participantes acreditam não acontecer. Foram registadas opiniões muito divergentes quanto ao apoio do Estado na resolução dos problemas da prevenção do risco e da gestão da crise/emergência, assim como na manutenção da capacidade técnica das instituições.

TABELA IV - Sugestões para aumentar a eficácia das políticas e da praxis na gestão do risco e das crises.

\begin{tabular}{|c|c|}
\hline \multirow{5}{*}{$\begin{array}{l}\text { Reforçar a } \\
\text { prevenção }\end{array}$} & - Clarificação de conceitos e utilização de designações em português; \\
\hline & $\begin{array}{l}\text { - Melhorar a fundamentação e a prática da avaliação do risco e integrar as } \\
\text { lições aprendidas; }\end{array}$ \\
\hline & - Melhorar o conhecimento local do risco de modo a adequar as estratégias; \\
\hline & $\begin{array}{l}\text { - Fazer cumprir legislação já existente como acontece com a gestão de } \\
\text { combustíveis; }\end{array}$ \\
\hline & $\begin{array}{l}\text { - Sensibilização da população para reforçar o envolvimento dos cidadãos } \\
\text { no processo para que depois possam ser responsabilizados. }\end{array}$ \\
\hline \multirow{3}{*}{$\begin{array}{l}\text { Cultura das } \\
\text { organizações }\end{array}$} & - Reforçar o diálogo e a colaboração entre as organizações; \\
\hline & $\begin{array}{l}\text { - Obrigar as organizações a trabalharem para o bem comum, reforçando } \\
\text { a orientação do seu objeto para criar uma verdadeira cultura de } \\
\text { segurança e garantir a sustentabilidade ambiental; }\end{array}$ \\
\hline & $\begin{array}{l}\text { - A colaboração passaria também por "falarem todos a mesma linguagem", } \\
\text { isto é, terem uma mesma visão estratégica e abordagem tática das } \\
\text { emergências, de modo a evitar a ocorrência de desastres. }\end{array}$ \\
\hline \multirow{7}{*}{$\begin{array}{l}\text { Governança } \\
\text { dos riscos e } \\
\text { das crises }\end{array}$} & $\begin{array}{l}\text { - Junção numa única entidade da responsabilidade da prevenção e do } \\
\text { combate aos incêndios florestais; }\end{array}$ \\
\hline & $\begin{array}{l}\text { - Maior liberdade/flexibilidade do comando das operações mas com uma } \\
\text { maior exigência/formação dos intervenientes; }\end{array}$ \\
\hline & $\begin{array}{l}\text { - Envolver as populações locais na gestão do risco e das crises pois têm } \\
\text { conhecimento e competências que poderiam ser relevantes para uma } \\
\text { prevenção e gestão eficiente; }\end{array}$ \\
\hline & $\begin{array}{l}\text { - Integrar o conhecimento tradicional das populações locais para aumentar } \\
\text { a eficácia da prevenção e da gestão; }\end{array}$ \\
\hline & - Investir mais na formação dos operacionais; \\
\hline & $\begin{array}{l}\text { - Fomentar a colaboração entre municípios para gerir riscos que são } \\
\text { comuns assim como suportar abordagens semelhantes; }\end{array}$ \\
\hline & $\begin{array}{l}\text { - Reforçar a participação dos investigadores, operacionais e populações na } \\
\text { prevenção e na gestão das crises para otimizar competências e recursos. }\end{array}$ \\
\hline
\end{tabular}

Avaliação da comunicação e colaboração entre instituições: os exemplos das cheias/ inundações e dos incêndios florestais

Em relação ao risco de cheia/inundação, os participantes consideraram que a comunicação e a colaboração entre as instituiç̃̃es é, em geral, complexa e muito limitada. Embora tivessem sido relatadas algumas experiências de boa colaboração, há inúmeras possibilidades de melhorar a situação. Foi mesmo sugerido que as instituições "devem colaborar mais entre si e não 


\section{Realidades e desafios na gestão dos riscos \\ - Diálogo entre ciência e utilizadores -}

TABELA V - Opinião sobre o esquema conceptual.

\begin{tabular}{|l|c|c|c|}
\hline \multicolumn{1}{|c|}{ Parâmetros de avaliação } & $\begin{array}{c}\text { Não } \\
\text { (\%) }\end{array}$ & $\begin{array}{c}\text { Sim } \\
\text { (\%) }\end{array}$ & $\begin{array}{c}\text { NR/ NS } \\
\text { (\%) }\end{array}$ \\
\hline Complexo & 48 & 52 & \\
\hline Compreensivel & 9 & 91 & \\
\hline Apresenta algum avanço face aos modelos existentes & 13 & 83 & 4 \\
\hline $\begin{array}{l}\text { Permite um melhor suporte da prevenção dos riscos e consequente } \\
\text { redução dos danos }\end{array}$ & 22 & 74 & 4 \\
\hline \begin{tabular}{l} 
Interliga bem a questão conceptual \\
\hline $\begin{array}{l}\text { O esquema conceptual permite suportar todo o tipo de opções } \\
\text { técnicas }\end{array}$
\end{tabular} & 26 & 70 & 4 \\
\hline NR-Não respondeu; NS-Não sabe & 43 & 9 \\
\hline
\end{tabular}

TABELA VI - Opiniões sobre a governança do risco e das crises.

\begin{tabular}{|c|c|}
\hline Questões & \%* \\
\hline A atual política de prevenção do risco envolve pouco os cidadãos & 73 \\
\hline O município representa a melhor escala para fazer prevenção dos riscos & 68 \\
\hline $\begin{array}{l}\text { A comunicação entre os diferentes atores institucionais com responsabilidades na } \\
\text { prevenção dos riscos e gestão das crises/emergências permite a apresentação } \\
\text { de sugestões para aumentar a eficácia da atuação }\end{array}$ & 64 \\
\hline $\begin{array}{l}\text { Há dificuldade de cooperação entre entidades privadas e instituições públicas } \\
\text { com responsabilidade na prevenção do risco }\end{array}$ & 59 \\
\hline $\begin{array}{l}\text { A comunicação e colaboração entre as instituições com responsabilidade na gestão } \\
\text { dos riscos e das crises/emergências é complexa e difícil }\end{array}$ & 59 \\
\hline O município representa a melhor escala para gerir as crises/emergências & 50 \\
\hline $\begin{array}{l}\text { Geralmente, não encontro nos organismos do Estado o apoio para a resolução dos } \\
\text { problemas da prevenção do risco e da gestão da crise/emergência }\end{array}$ & 32 \\
\hline $\begin{array}{l}\text { Nos últimos anos as instituições do Estado perderam capacidade de auxiliar } \\
\text { tecnicamente as entidades com responsabilidade na prevenção do risco }\end{array}$ & 32 \\
\hline $\begin{array}{l}\text { A articulação com a hierarquia superior da proteção civil apenas é necessária para } \\
\text { a gestão das crises/emergências }\end{array}$ & 18 \\
\hline $\begin{array}{l}\text { A informação necessária para a gestão do risco e das crises é partilhada de uma } \\
\text { forma adequada entre as instituições do Estado }\end{array}$ & 18 \\
\hline $\begin{array}{l}\text { O município é a melhor escala para promover a prevenção dos riscos e não é } \\
\text { necessária a articulação com estruturas hierarquicamente superiores }\end{array}$ & 9 \\
\hline $\begin{array}{l}\text { A proteção civil deverá assegurar a segurança das populações pelo que os cidadãos } \\
\text { não terão de desenvolver medidas de prevenção e autoproteção }\end{array}$ & 5 \\
\hline
\end{tabular}




\section{Diálogo entre a ciência e os utilizadores. Potencialidades e fragilidades na temática dos riscos}

estarem preocupadas com a sua "quinta", ou seja devem unir esforços no mesmo sentido e não virarem as costas umas às outras como, por vezes, se verifica" (opinião de um participante). Os progressos mais significativos ocorreram ao nível da troca de informação, nomeadamente meteorológica, sendo necessário avançar para uma maior partilha de conhecimento científico, superação de algumas barreiras burocráticas e simplificação de procedimentos. Para alguns dos participantes, uma das razões que justificam os problemas de comunicação e colaboração é a existência de demasiados intervenientes no processo. É possível melhorar a prevenção, a gestão da crise, o sistema de monitorização e os sistemas de aviso à população.

Em relação aos incêndios florestais, a colaboração entre instituições foi considerada adequada por $30 \%$ dos inquiridos Outros intervenientes não manifestaram uma opinião tão positiva, embora reconheçam ter havido progressos. Durante o combate, a articulação é adequada, mas falta na vigilância pós incendio e também no caso da prevenção. Todavia, ainda persiste uma cultura de competição entre instituições e não de colaboração. Os Planos Municipais de Defesa da Floresta Contra Incêndios foram referidos como um bom exemplo da importância de colaboração de várias entidades no planeamento da Defesa da Floresta Contra Incêndios.

Foram várias as sugestões apresentadas para aumentar a eficácia da gestão do risco de incêndio florestal e da supressão:

- Reforçar a colaboração entre os 3 pilares do Sistema de Defesa da Floresta Contra Incêndios e envolver como $4 .^{\circ}$ pilar os municípios, pois a prevenção e o combate são vistos como atividades distintas e desconexas mas deveriam estar integradas e serem concertadas;

- Deveria existir o cumprimento da legislação, no âmbito da prevenção, pois por vezes há o levantamento de contraordenações, mas os processos não são instruídos;

- Melhor programação das atividades de prevenção pois, por vezes, no momento de, por exemplo, colocar vigilantes no terreno e ainda não se sabem os recursos existentes;

- Deveria haver mais uniformização doutrinária.

\section{A relação dos utilizadores com os investigadores}

A avaliação da produção científica na temática dos riscos suscitou opiniões divergentes, com apenas $44 \%$ dos participantes a considerarem que a produção científica geralmente é útil e responde às necessidades dos utilizadores. Um dos participantes revelou desconhecer o trabalho dos investigadores.

As experiências ao nível da comunicação entre a comunidade científica e os utilizadores também suscitaram opiniões muito diversas por parte dos participantes (TABELA VII). Embora a maior parte dos inquiridos tenha avaliado positivamente a sua comunicação com os cientistas/investigadores, apenas $9 \%$ dos participantes revelaram ter uma boa colaboração baseada num modelo de investigação-ação-investigação procurando responder aos desafios societais. A maior frequência de respostas refere-se aos inquiridos que, embora avaliem como boa a sua relação com os cientistas, são da opinião que a investigação não é utilizada para fins operacionais. Nalguns casos, a comunicação restringe-se à participação em congressos.

Para aumentar a frequência da comunicação entre as duas comunidades e promover uma maior partilha de informação e de saberes, foi sugerida a realização de seminários temáticos, como aquele em que participaram e em que puderam expressar as suas opiniões, a implementação de trabalho conjunto no terreno e, ainda, a realização de ações de formação e de divulgação.

Ampliar a visibilidade e o impacto da investigação científica na resolução de problemas concretos da sociedade requer: uma melhor divulgação e acesso ao trabalho científico; direcionar a investigação para questões que respondam a necessidades concretas dos utilizadores, isto é, procurar que a ciência responda a problemas e desafios fundamentais da sociedade; e utilizar linguagem acessível. 


\section{Realidades e desafios na gestão dos riscos \\ - Diálogo entre ciência e utilizadores -}

TABELA VII - Avaliação da comunicação entre os utilizadores e os investigadores.

\begin{tabular}{|l|c|}
\hline \multicolumn{1}{|c|}{ Tipo de relação } & $\% *$ \\
\hline $\begin{array}{l}\text { Boa comunicação, boa colaboração mas os resultados da investigação não são } \\
\text { utilizados embora sejam adequados para a prática da gestão do risco e da } \\
\text { emergência }\end{array}$ & 39 \\
\hline $\begin{array}{l}\text { Relação fraca ou esporádica e apenas através da participação em congressos e } \\
\text { seminários }\end{array}$ & 17 \\
\hline $\begin{array}{l}\text { Boa comunicação, boa colaboração. É adotado um modelo de investigação-ação- } \\
\text { investigação para aumentar a eficácia de procedimentos }\end{array}$ & 9 \\
\hline $\begin{array}{l}\text { Boa comunicação, boa colaboração. O uso da investigação é considerado útil e aceite } \\
\text { pra uso operacional }\end{array}$ & 9 \\
\hline $\begin{array}{l}\text { Boa comunicação, boa colaboração mas os resultados da investigação não são } \\
\text { utilizados pois não respondem às necessidades dos utilizadores }\end{array}$ & 9 \\
\hline Relação fraca ou esporádica e apenas por solicitação dos investigadores & 9 \\
\hline Relação fraca ou esporádica e por solicitação dos utilizadores & 4 \\
\hline Outra & 100 \\
\hline Nenhuma relação & 4 \\
\hline Total & *As percentagens referem-se às respostas dos utilizadores que “concordaram” ou “concordaram totalmente” \\
\hline com o conteúdo dos itens mencionados. & 9 \\
\hline
\end{tabular}

\section{Conclusão}

A realização do seminário "Diálogos entre Ciência e Utilizadores: Realidades e desafios na gestão do risco" para discutir uma proposta de conceptualização dos riscos naturais e antrópicos e para compreender as dificuldades com que os atores sociais se confrontam atualmente na sua gestão, foi muito bem acolhida pelos utilizadores, que claramente se empenharam na discussão e na apresentação da sua experiência ao nível da prevenção dos riscos, da preparação e da gestão das emergências.

A discussão em grupo permitiu conhecer opiniões diversas motivadas por questões de perceção, mas também de perspetiva. Os resultados foram francamente positivos e traduziram-se em três direções distintas:

- Contribuíram para motivar os proponentes do modelo a continuar a sua reflexão sobre a conceptualização proposta e a agilização da sua operacionalização para que possa ser mais eficaz. Foi pedido aos investigadores que vejam para além de meras discussões académicas e epistemológicas;

- Possibilitaram conhecer as fragilidades no diálogo entre os investigadores e utilizadores;

- Permitiram que os próprios utilizadores tivessem identificado algumas fragilidades ao nível da governança que deverão fazer refletir e motivar a intervenção dos investigadores. 
Os utilizadores consideraram importante a clarificação e a estabilização da terminologia e a existência de um modelo conceptual do risco que traduzisse a realidade que fosse aceite por todos os operacionais. A maior parte das propostas para melhorar a prática da gestão de riscos e de crises referiram-se à governança, tendo sido sugerido que os planos deveriam ser simplificados e o seu conteúdo adequado às realidades locais mantendo o rigor. Foi salientado que a colaboração entre instituições apresenta várias fragilidades. Importa exortar as organizações a dialogar e a trabalhar em conjunto, procurando colocar o interesse público acima dos corporativos de modo a permitir um conhecimento mais integrado da complexa realidade dos riscos e da definição de procedimentos mais eficazes (TEDIM et al., 2012).

Os resultados obtidos, quer através do questionário quer da discussão em grupo, evidenciam fragilidades na colaboração entre os investigadores e os utilizadores, a qual está muito aquém do que seria esperado e mesmo aconselhável, numa ótica de otimização de recursos humanos e materiais. Os casos de sucesso parecem muito mais baseados em estratégias individuais, do que numa cultura efetiva de cooperação. É fundamental reforçar a comunicação efetiva e produtiva, uma vez que a gestão dos riscos e das crises é cada vez mais complexa, requerendo conhecimentos multidisciplinares que se encontram dispersos por diversas áreas de investigação e de atuação.

O desenvolvimento de sinergias entre organizações, assim como entre os investigadores e utilizadores, é essencial e deve assentar no diálogo. Este tem de ser um processo bidirecional, em que os investigadores e os utilizadores procurem compreender os diversos pontos de vistas, o funcionamento dos processos e quais os resultados que pretendem alcançar (EASAC, $\mathrm{s} /$ data). Este diálogo pode servir vários propósitos, nomeadamente: aumentar a visibilidade e aplicação social da ciência; orientar a investigação para a resolução de problemas específicos da sociedade; facilitar o acesso à produção de conhecimento científico; conhecer os problemas que os utilizadores enfrentam no dia-a-dia e a resposta que necessitam dos cientistas; otimizar procedimentos, avaliar e corrigir políticas.

Um método de investigação participada é fundamental para que a gestão não seja orientada meramente para a concretização de determinadas metas ("output", como p. ex., elaborar um plano de emergência) mas sim para atingir determinados resultados ("outcome") ao nível de desempenho ou realizações. "Os investigadores têm de aceitar o desafio de melhor comunicar a sua investigação em formatos preferidos pelos utilizadores, dedicar mais tempo a "educar" os utilizadores a compreender a usar os resultados produzidos, enquanto os utilizadores têm de "educar" os investigadores a produzirem conhecimento mais relevante e útil” (de la VEGA-Leinert e SCHRöter, 2008: p. 30). Só desta forma se poderão obter os maiores benefícios da interação entre a ciência e os utilizadores, como suporte fundamental do desenvolvimento da sociedade.

\section{Referências bibliográficas}

de la Vega-Leinert, Anne Cristina and Schröter, Dagmar (2008) - Stakeholder dialogue as a communication and negotiation tool in scientific inquiry, in CARVALHO, Anabela (ed.) Communicating Climate Change: Discourses, Mediations and Perceptions.Braga: Centro de Estudos de Comunicação e Sociedade, Universidade do Minho, p. 13-33 Available from: http://www.lasics.uminho.pt/ojs/index.php/climate_change.

EUROPEAN ACADEMICS SCIENCE, Advisory Council (s/data) - EASAC Guidelines: Good Practic in the Dialogue between Science Academies and Policy Communities http://www.easac.eu/ fileadmin/ppt/Science-Policy-Dialogue/Short_EASAC_Guidelines_PDF.pdf.

Julião, R. P., Nery, F., Ribeiro, J. L., Branco, M. C. e Zêzere, J. L. (2009) - Guia metodológico para a produção de cartografia municipal de risco e para a criação de sistemas de informação geográfica (sig) de base municipal. Lisboa, Ed ANPC, co-Ed. DGOTDU e IGP, 91 p. 


\section{Realidades e desafios na gestão dos riscos \\ - Diálogo entre ciência e utilizadores -}

Tedim, Fantina; Barros, Ivo; Carvalho, Salete; Felguelras, João (2012) - Os incêndios florestais em Áreas Protegidas: uma realidade com distintas representações sociais, in TEDIM, F. e Paton, D., A dimensão social dos incêndios florestais: para uma gestão sustentável, Estratégias Criativas, Porto, p. 101-128.

VERDE, J. C. (2008) - Avaliação da perigosidade de incêndio florestal. Dissertação de Mestrado, Universidade de Lisboa, Faculdade de Letras, Departamento de Geografia.

Verde, J. C. e Zêzere, J. L. (2010) - “Assessment and validation of wildfire susceptibility and hazard in Portugal". Natural Hazards and Earth System Science, Vol. 10/n. ${ }^{\circ} 3$, p. 485-497.

Welp, Martin; de la Vega, Leinerta Anne, Stoll-KleEmannb, Susanne; C. Jaegera, Carlo (2006) Science-based stakeholder dialogues: Theories and tools Global Environmental Change 16, p. $170-181$.

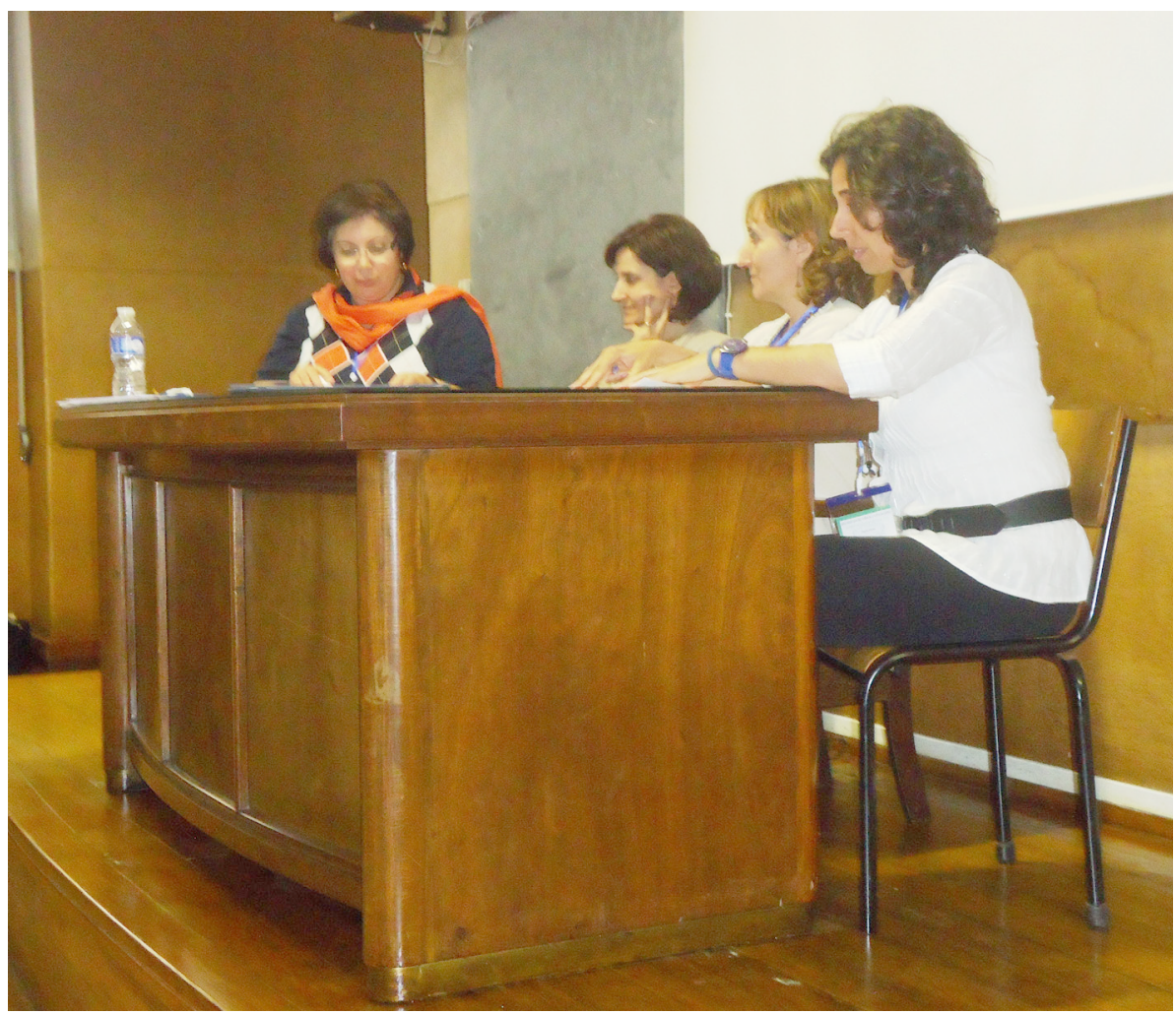

